\title{
Reviews
}

\section{From Anxiety to Meltdown: How Individuals on the Autism Spectrum Deal with Anxiety, Experience Meltdowns, Manifest Tantrums, and How You Can Intervene Effectively}

Deborah Lipsky

Jessica Kingsley Publishers, 2011, £13.99, pb, 240 pp. ISBN: 9781849058438

In recent years there has been a glut of publications on autism outside of mainstream medical literature. These have included carers' accounts and personal narratives. First-person accounts of Asperger syndrome seek to provide an alternative narrative to 'deficient focused' medical accounts. Perspectives are reversed in these texts. The persons with autism describe tentatively, but with increasing confidence, how they see both themselves and the 'neurotypical' world they find themselves in. In these books the exotic is made ordinary and understandable, and they help diminish the stereotype of the 'autist' (their preferred term) as the 'other', which is often the stance of other people writing about people with autism.

Deborah Lipsky represents the best of this tradition of 'neurodiversity' in her blunt, sometimes wry, exploration of anxiety, which she believes is central to the autistic state. She strips away the veneer from habitual beliefs and assumptions about autism. The book reflects its practical roots in a training manual on management of 'meltdowns'. She provides realistic appraisal as well as practical advice in managing anxiety. Her pragmatic account is far removed from more typical narratives of disability with their focus on transformation and redemption. Her triumphs are small, her assessments shrewd, and her reflections often self-deprecatory. There is vein of healthy humour leavening some very real distress and bewilderment.

She is at her more secure in the experiential explorations of her own anxiety and those of other people with autism. She describes at length her need for 'scripts' in every situation, the need for predictability and accountability. The apparent slippage in the real world which to her countenances injustices and condones irregularity leaves her nonplussed.

It is when she delves into the jargon of neurobiology that she falters. To the medical profession this is a closed world with its own discourse and its own scripts, one which does not lend itself to easy translation. This detour aside, the book's strength is in formulating strategies to identify triggers for anxiety and evolving solutions.

Robust copy-editing may have avoided repetitions throughout. Despite this, this book is of value to people with autism, their carers and professionals. If the asides on Cold War politics or the far-out evolutionary theories about an 'autistic super-race' leave you bemused, hang in there, for the book delivers, plumbing hidden depths in both showing and telling.

Anupama lyer is Consultant in Adolescent Developmental Disabilities, Adolescent Directorate, St Andrew's Hospital, Northampton, UK, email: iyeranu21@yahoo.co.uk

doi: $10.1192 /$ pb.bp. 111.037234

\section{Brief Dynamic Interpersonal Therapy: A Clinician's Guide}

Alessandra Lemma, Mary Target \& Peter Fonagy Oxford University Press, 2011, E19.99, pb, 288 pp. ISBN: 9780199602452

The first thing that struck me about this book was the title. Was this a new take on interpersonal therapy? This was made clear within the first page of the preface, with the short answer being 'no'. Whereas the focus of dynamic interpersonal therapy is on relationships in the present, it aims to facilitate understanding of these in the context of past experiences using a psychodynamic paradigm.

Dynamic interpersonal therapy is not 'psychoanalysis-lite', and neither does it pretend to be. Instead, it is a semistructured, focused psychotherapy designed for treatment of mood disorders. Although 'brief' is not included in the name of the therapy, it is reflected in the 16-session structure. This aims to provide an 'interpersonal affective focus', with a view to using this as a foundation for understanding current difficulties, before dedicating the final sessions to the ending of therapy. Self-rating scales are used at the start of each session, both to track change and to aid reflection of current difficulties.

The book is easy to read and - as well as a detailed description of dynamic interpersonal therapy - provides an aide mémoire for basic psychodynamic theory, which ensures that it does not alienate readers with jargon. It consists of 11 well-structured chapters, which take the reader from considering and assessing suitability for dynamic interpersonal therapy, to the initial phases and formulation, through the middle part of the therapy (including techniques and working within the transference), and finishing aptly with the ending phase. Diagrams are used to aid understanding of concepts and clinical examples illustrate the application of the techniques. There is also a helpful chapter entitled 'When things go wrong', which addresses useful learning points that transcend the remit of dynamic interpersonal therapy.

As well as being a well-written manual for the dynamic interpersonal therapy training course, this book is also likely to stimulate interest among both psychotherapists and general adult psychiatrists with a penchant for psychodynamic practice. And because dynamic interpersonal therapy has been selected as the brief psychodynamic protocol that will be provided nationally in the Improving Access to Psychological Therapies programme, it is certainly something worth learning more about.

Steven Birrell is ST4, General Adult Psychiatry, Queen Margaret Hospital, Dunfermline, Fife KY12 OSU, UK, email: stevenbirrell@nhs.net

doi: 10.1192/pb.bp.111.037002

\section{Best Practices in Medical Teaching}

Stephen M. Stahl \& Richard L. Davis

Cambridge University Press, 2011, E27.99, pb, 192 pp. ISBN: 9780521151764

This book sets out to consider whether the focus of medical education should be the content of education, the medical 
educator, or the learner. The process of presentation is taken as central to medical education and therefore the authors set out to help educators improve in this area.

There are five chapters. The book is clearly signposted, to the point and very practical. Each chapter concludes with multiple-choice questions to check what you have learnt and proposes a way to assess your own performance in the areas find that a helpful way of charting their progress, especially if they have set themselves some educational goals in this area. A feature I liked was the 'Bioboxes', which provide a brief biography of the key players, as they add some context to tried to give evidence and justify the suggestions made, and linked them either to some theoretical underpinning principles or to research.

The first chapter provides guidance on how to prepare slides, especially for complex information, and includes a short section on workshops. The next chapter is an overview of using audience psychology to plan presentations. In some ways this may have been a useful opening chapter as it raises key issues about learners and the different ways in which people learn. Chapter three is about how to deliver a lecture effectively, with some good tips, and chapter four discusses measuring outcomes and ensuring success. I found this a less helpful chapter. There was a focus on learning as acquiring and mastering information. Medical education, especially in psychiatry, includes attitudinal and reflective learning, and related outcome evaluations were not touched upon. covered. I was less keen on the scoring method, but some may where the person's ideas came from. The book consistently

The final chapter focuses on how to supplement teaching to better support learning through a range of different methods and mechanisms. The authors provide a worked example of their own programme in psychopharmacology. The principles are easily transferable and the suggestion about how to keep track of students' progress was particularly helpful.

The foreword of the book promises: 'this book not only describes how to become a powerful public speaker but also provides a living example of best practices in medical education'. That is one of my two gripes with this book. Medical (and indeed any type of) education is so much more than powerful public speaking. No presentation, however brilliant, is going to make up for a lack of other teaching skills. The focus on presentations over other teaching techniques and knowledge as the key outcome of learning are perhaps misleading, as the authors do acknowledge that lectures and presentations are only part of the repertoire. The second issue is minor and somewhat pedantic. It relates to the brief section on addressing cultural diversity within potential audiences. I found the suggestions to address this superficial.

Without a doubt, this book provides excellent support in how to deliver great presentations and for that I would recommend it.

Nisha Dogra is Professor of Psychiatry Education and Consultant in Child and Adolescent Psychiatry, Greenwood Institute of Child Health, Westcotes House, Westcotes Drive, Leicester LE3 OQU, UK, email:nd13@le.ac.uk

doi: 10.1192/pb.bp.111.037044

\section{Outcome Measurement in Mental Health: Theory and Practice}

\section{Compulsive Buying: Clinical Foundations and Treatment}

Astrid Müller \& James E. Mitchell (eds)

Routledge, 2011, $E 22.46$ pb, 306 pp.

ISBN: 9780415876421

\section{Handbook of Depression (2nd edn)}

Ian H. Gotlib \& Constance L. Hammen (eds) Guilford Press, 2010, US $\$ 45.00$ pb, 708 pp.

ISBN: 9781609181505

\section{Understanding Panic Attacks and Overcoming Fear (3rd edn)}

Roger Baker

Lion UK, 2011, $€ 7.99$ pb, 176 pp.

ISBN: 9780745955452

\section{Cognitive Behavioural Therapy with Older People: Interventions for those With and Without Dementia}

lan Andrew James

Jessica Kingsley Publishers, 201, £24.99 pb, 256 pp.

ISBN: 9781849051002
Tom Trauer (ed.)

Cambridge University Press, 2010, $£ 55.00$ hb, 276 pp.

ISBN: 9780521118347

\section{Self-Harm and violence: Towards Best Practice in Managing Risk in Mental Health Services}

Richard Whittington \& Caroline Logan (eds)

John Wiley \& Sons, 2011, E32.99 pb, 328 pp.

ISBN: 9780470746066

\section{Schizophrenia (3rd edn)}

Ming T. Tsuang, Stephen V. Faraone \& Stephen J. Glatt Oxford University Press, 2011, £13.99 pb, 150 pp.

ISBN: 9780199600915

\section{An Introduction to Modern CBT: Psychological Solutions to Mental Health Problems}

Stefan G. Hofmann

Wiley-Blackwell, 2012, E29.99 pb, 236 pp.

ISBN: 9780470971758 